\title{
1 Nest monitoring does not affect nesting success of Whinchats
}

\section{Saxicola rubetra}

3 Jennifer A. Taylor ${ }^{1}$, Ian G. Henderson ${ }^{2}$, Ian R. Hartley ${ }^{1}$

4

${ }^{1}$ Lancaster Environment Centre, University of Lancaster, Lancaster, LA1 4YQ, UK. E-mail: j.taylor7@lancaster.ac.uk; i.hartley@lancaster.ac.uk

${ }^{2}$ British Trust for Ornithology, The Nunnery, Thetford, IP24 2PU, UK. E-mail: ian.henderson@bto.org

\section{Abstract}

9 It is important to assess the effect that research activities may have on animals in the wild, especially 10 when key parameters, such as breeding success, could potentially be influenced by observer activity. 11 For birds, some studies have suggested that nest monitoring can increase the chances of nest failure

12 due to predation, while others suggest that human nest visits may actually deter mammalian predators.

13 Nest monitoring visits can also influence breeding success more indirectly by altering parental

14 provisioning behaviour. Here, the influence of monitoring activities on nest success in a ground nesting, grassland bird, was examined. First, during the egg phase, a sample of nests were not visited between the initial finding event and the estimated hatching date; instead the nest status was assessed from afar. Daily Survival Rates (DSR) for these nests were compared to nests visited every two days. Second, during the nestling phase, the effects of observer nest visits on parental provisioning behaviour were determined. Nest visits were found not to significantly affect egg DSR and parental provisioning was disrupted for a maximum of 20 minutes ( $0.52 \%$ of the nestling period) following an observer visit. Therefore we conclude observer visits have minimal effects on nest success in Whinchats.

Accurate quantification of breeding success in birds almost always requires nest visits by the researcher. There has long been concern that these necessary visits may impact a bird's breeding success, biasing estimates and possibly reducing breeding success in the very species scientists are aiming to conserve or understand (Reynolds \& Schoech 2012). Reviews on the topic have found that effects of researcher visits to nests vary widely among species, sometimes even within the same habitat (Weidinger 2008; Ibanez-Alamo et al. 2012). It is, therefore, particularly important for researchers to monitor the effect of disturbance from their research activities and use this information 
when interpreting their findings and when planning future research projects (O'Grady et al. 1996; Price 2008; Reynolds \& Schoech 2012).

Disturbance by researchers during nest monitoring activities can potentially influence the outcome of a nest either directly, by encouraging nest desertion (Tremblay \& Ellison 1979; Piatt et al. 1990), or indirectly, by increasing the risk of predation. Parents may be forced to leave nests unguarded (Strang 1980) and researchers may draw attention to a nest by creating olfactory or visual trails leading to it (Whelan et al. 1994) and eliciting conspicuous parental defence behaviours such as alarm calling (Major 1990; Weidinger 2008; Jacobson et al. 2011). A review by Götmark (1992) found researcher activities had reduced nesting success in $49 \%$ of studies but a recent meta-analysis on 25 species from six orders found that researcher visits did not affect the probability of nest failure through predation (Ibanez-Alamo et al. 2012). In fact, nest visits by observers may actually have reduced the risk of predation for passerines and ground nesting birds, as the presence of humans may deter mammalian predators (Macivor et al. 1990; Ibanez-Alamo \& Soler 2010; Ibanez-Alamo et al. 2012, but see Skagen et al. 1999).

Nest monitoring visits also can affect breeding success by altering the parents' behaviour. Animals tend to respond to human disturbance as though it was a potential predation event (Frid \& Dill 2002; Beale \& Monaghan 2004; Price 2008). This may lead to a temporary suspension of nestling provisioning (Wheelwright \& Dorsey 1991; Michl et al. 2000; Zhao 2005; studies reviewed in Lima 2009; Tilgar et al. 2011; Paclik et al. 2012; Ghalambor et al. 2013; Mutzel et al. 2013; Vitousek et al. 2014; but see Hakkarainen et al. 2002) and a corresponding increase in vigilance, nest guarding and nest defence behaviours (Montgomerie \& Weatherhead 1988; Wheelwright \& Dorsey 1991; reviewed in Frid \& Dill 2002 and Price 2008; Caro 2005; Mutzel et al. 2013). This behaviour is potentially adaptive, as the risk of the predator finding the nest is reduced (Eggers et al. 2005, 2008), the parent can invest more time and energy in active nest defence (Montgomerie \& Weatherhead 1988) and the parents' survival chances may also be increased (Lima 2009). There is, however, a trade-off in that the food supply to the nestlings is reduced, which can impact offspring condition and possibly their future survival chances and reproductive output (Trivers 1972; Clark \& Ydenberg 1990; Dale et al. 1996; Michl et al. 2000; Frid \& Dill 2002; Price 2008; Martin \& Briskie 2009; Lima 2009). When disturbance is repeated and frequent, the temporary suspension of feeding has the potential to cause harmful cumulative consequences, with young fledging at smaller sizes (Scheuerlein \& Gwinner 2006; Thomson et al. 2006; Tilgar et al. 2011). Some studies found that parents will compensate by 63 provisioning at a higher rate after a predation threat (Paclik et al. 2012; Mutzel et al. 2013 but see 64 Tilgar et al. 2011) and by provisioning larger load sizes (Eggers et al. 2008; Lima 2009). However, 
there is limited scope for compensation as a nestling's digestive system can only process a certain quantity of food within a given time period (Eggers et al. 2005).

The response of the parents to a perceived 'predation threat' will vary depending on the balance between the potential 'value' of the nestlings and on the perceived risk to the parents (Trivers 1972; Montgomerie \& Weatherhead 1988; Clark \& Ydenberg 1990). The potential 'value' of the nestlings depends on nestling age (Dale et al. 1996; Michl et al. 2000; Pavel \& Bures 2001; Zhao 2005), brood size (Tilgar \& Kikas 2009), nestling condition (Michl et al. 2000), the parent's investment so far (Dale et al. 1996; Pavel \& Bures 2001) and the potential for re-nesting (reviewed by Martin 1987; Michl et al. 2000). For example, parents may risk more and resume feeding earlier for larger broods (Tilgar \& Kikas 2009) or nestlings in better condition (Michl et al. 2000) and female parents may take more risks than male parents for younger nestlings if they have invested more in the nestlings up to this stage (Michl et al. 2000; Pavel \& Bures 2001; Dale et al. 1996). The perceived risk to each parent may depend on the type of predator (Bures \& Pavel 2003; Martin \& Briskie 2009; Tilgar et al. 2011; Ippi et al. 2013), the sex, size, condition and experience of the parent (Martindale 1982; Montgomerie \& Weatherhead 1988; Lima 2009), and the protection offered by the surrounding nesting habitat (Eggers et al. 2008; Lima et al. 2009; Martin \& Briskie 2009). For situations where a species can actively defend the nest against a predator, parents may remain close to the nest following a predation threat, and restrict their foraging range (Marzluff 1985; Martindale 1982; Hakkarainen et al. 2002; reviewed in Lima 2009). The parent that is most effective at defending the nest often remains closer to the nest than their partner (e.g. Gila Woodpecker, Martindale 1982). In species where neither parent is actively able to defend the nest contents against predators, the optimal strategy is likely to be nest crypsis and the minimisation of parental activity around the nest (Burhans 2000; Bures \& Pavel 2003).

In this paper we aim to explore the potential effects of visiting Whinchat nests to monitor reproductive success. Daily survival rates during the egg phase will be compared between nests which received visits every two days, and those that were visited only once. Previous studies suggest that where the main predators are mammalian, as appears to be the case in this study (Taylor et al. in prep), the nest predation rates may be reduced by more frequent monitoring visits. Additionally, we quantify the provisioning behaviour of parents in relation to researcher nest visits. It is predicted that the Whinchat parents will reduce nestling provisioning until the perceived threat has diminished to avoid disclosing the nest location and to allow more time to be allocated to nest guarding and vigilance behaviours. To this end, it is also predicted that parents are likely to remain in the vicinity of the nest immediately after a predation threat, to enable earlier nest predator detection, and will avoid long foraging trips until the perceived threat has diminished.

\section{Methods}


101 The study site was located on the west section of Salisbury Plain, Wiltshire, in southwest England $\left(51^{\circ} 11^{\prime} 52^{\prime \prime}-51^{\circ} 16^{\prime} 4^{\prime \prime N} ; 1^{\circ} 57^{\prime} 32^{\prime \prime}-2^{\circ} 9^{\prime} 32^{\prime \prime W}\right)$. The site has been under military ownership since the early $20^{\text {th }}$ century and the west section is predominantly used by the military for training. The majority of the area is classified as agriculturally unimproved grassland (Walker \& Pywell 2000)..

Nest visit experiment during egg phase

Nests were found for all known breeding pairs within the study site. The locations of all nests were recorded using a Geographical Position System (GPS) reading at the nest site. Nests were also marked in the field using an unobtrusive $50 \mathrm{~cm}$ bamboo cane 2-3 $\mathrm{m}$ from the nest. In 2014, nests were paired in the order of finding, with alternate nests being designated as 'visit' nests and 'distance-visit' nests. Daily watches of breeding adults early in the season and recording of behaviour and nest building activity enabled hatching date to be estimated to within two days. Visit nests were visited every two days and distance-visit nests were not visited after the initial nest finding event, until the estimated hatching date. Distance-visit nests were assessed from a distance every two days, to determine whether they were still active, by observing the female leaving the nest and returning to incubate, or via alarm calling parents on the territory when the researcher was in the vicinity. After the initial nest

116 finding, the observer never went closer than $20 \mathrm{~m}$ to the distance-visit nests and, in general, stayed at 117 least $80 \mathrm{~m}$ away.

\section{Disturbance experiment during nestling provisioning}

119 Thirty-nine monitored nests were included in the experiment: 20 in 2013 and 19 in 2014. The researcher approached the nest and set up a small video camera on a tripod, pointing at the nest, one metre away. Marker canes were placed into the ground at 20,40,60 and $80 \mathrm{~m}$ from the nest, to facilitate distance estimation. The observer then retreated to at least $80 \mathrm{~m}$ to watch the parents during their subsequent provisioning activities. The video camera recorded provisioning visits by the parents, and the observer recorded the parents' distances from the nest once every minute for the hour following the disturbance event. To account for the variable nature of provisioning rates the experiment was conducted on each nest three times, when the nestlings were 6, 7 and 8 days old; the period of maximum provisioning rate. Provisioning watches were conducted between 9 am to $6 \mathrm{pm}$, which avoided times when feeding rates may be particularly high or when the need to feed nestlings would be more urgent. Watches were not conducted in moderate to heavy rain. Due to weather conditions, access restrictions and predation of nests, there were some cases where it was not possible to undertake all three replicates ( 25 nests with 3 days of data, 8 nests with 2 days of data and 4 nests with 1 day of data). Provisioning data from two nests were excluded: one because of technical 
133 problems with the camera and one because the local topography prevented observations without

134 disturbing the birds.

\section{Nestling condition}

Six days after hatching, all nestlings were weighed and had their tarsi measured, although due to occasional access restrictions, this occurred a day either side in a minority of cases. An index of body condition was calculated by regressing an individual's weight $(\mathrm{g})$ against their size (measured by tarsus (mm)) and by extracting the residuals for use in the analysis (Davies et al. 2014). Body condition was normally distributed. The necessary assumptions that mass and tarsus length were linearly related (LM: Est $=0.813+/-0.021, \mathrm{p}<0.0001, \mathrm{n}=385)$ and that condition was independent of tarsus length (Pearson's Product Moment Correlation Coefficient $(\mathrm{PMCC})=-1.56, \mathrm{df}=385, \mathrm{p}=1$ ) were upheld (Green 2001). Nestling body condition was then averaged for nestlings within a nest to produce a mean value per nest.

\section{Data analysis}

The data were analysed using the R statistical package version 2.3.1 (R Development Core Team 2014). A logistic exposure model (see Shaffer 2004), with 'visit' or 'distance-visit' as a factor, was used to assess the influence of nest visits on the Daily Survival Rate (DSR) for the egg phase of the breeding cycle. Only first broods were included in the analysis to avoid pseudo-replication. The time since the disturbance event was split into 12 five-minute periods, with the number of feeds calculated for each observation period and then averaged over the three replicates for each nest. Based on pilot data from 2012, five minutes was selected as long enough to allow provisioning events to occur, but short enough to detect the gradual pattern of change in provisioning rate after a predation event. The sex of the provisioning parent was determined in $98 \%$ of feeds. The number of feeds per five-minute period was positively skewed and therefore was square root transformed for use in the analysis. A Non-linear Least Squares (NLS) model of the form: asymptote/ $(1+\exp ((\operatorname{midpoint}-$ time since nest disturbance)/slope)), was used to produce an equation for the relationship between time since disturbance and parental provisioning rate to determine the length of time provisioning was disrupted. GAMMs were used to examine the variation in number of feeds with parental sex, brood size and nestling condition.

Linear Mixed Models (LMM) were used to assess the time until the first feed after nest disturbance (latency to feed), and how this varied due to parental sex, brood size and chick condition, with nest as the random effect. The latency to feed was positively skewed and therefore was square root transformed to an approximately normal distribution. The global model, which included two interaction effects of parental sex and brood size and parental sex and nestling condition, was 
simplified via backwards stepwise deletion using the drop1 command in $\mathrm{R}$ (Chambers 1992). For each nest, the mean latency to feed for both parents was calculated over the $1-3$ observation periods.

The percentage of time spent $20 \mathrm{~m}$ or less from the nest was investigated in the same way as the number of feeds: the data were split into 12 five-minute blocks of time. For each block the number of distance observations where a parent was $20 \mathrm{~m}$ or less from the nest was divided by the total number of distance observations for that parent within the five minute block. This percentage was then averaged for each 5 minute block over the 1-3 observation periods per nest. The percentage of time spent $20 \mathrm{~m}$ or less from the nests was selected because within $20 \mathrm{~m}$ was considered a distance that the parents could still see the nest, and any approaching predator from, well before the predator got close enough to attack, therefore suggesting a preference for nest guarding and vigilance. The percentage of time spent $20 \mathrm{~m}$ for less from the nest was positively skewed, however, transformation did not improve the distribution, and the final model residuals did not reflect any problems despite the skew.

\section{Results}

\section{Effect of nest visits on egg survival}

There was no significant difference in the Daily Survival Rate for the egg phase between visit and distance-visit nests (Logistic-exposure GLM: ANOVA, $\mathrm{p}=0.569, \mathrm{df}=122, \mathrm{n}=124$ observation intervals from 17 visit nests and 18 distance-visit nests).

\section{Effect of nest visits on parental provisioning behaviour}

The starting values for the NLS model were chosen based on Figure 1. To account for the repeated measures of the 12 five minute blocks for each nest, a global model with a random effect of nest was used (AIC = 618); this had a lower AIC than the global model with nest and year random effects (AIC $=620)$ and the global model without a random effect $($ AIC $=695)$. The model parameters are displayed in Table 1. Residual plots confirmed the model was a good fit. After a nest disturbance event, the parental provisioning rate increased up to a maximum level at around 20 minutes where it levelled off (S1). This asymptote translates to 1.12 feeds $(95 \%$ CI: $1.11-1.14)$ in five minutes.

\section{Variations in parental response to disturbance due to parental sex and nestling condition}

The global model allowed different smoothing slopes for the provisioning rates for each parental sex and included a parental sex and condition interaction and a brood size term. A model allowing the smoothing slope to change with nestling condition was too complex to fit with the data available: separately evaluating this model without the other variables indicated that there was not a significant change in slope with condition. A global model with a random effect of nest had an AIC of 1042, as opposed to a global model with year and nest as random effects, AIC $=1044$, and a global model 
without random effects, AIC $=1190$. Therefore only a random effect of nest was used. The best model had a smoothed term for time since disturbance, and included parental sex and brood size terms (Table 2). Brood size did not have a significant effect on the provisioning rate (GAMM: $p>0.223$ ) but it was included in all models as a control for variations in brood sizes between nests.

There was a marginally significant difference in the response of males and females, with males provisioning generally at a higher rate: (GAMM: Est $=0.0709+/-0.0292, \mathrm{p}=0.0152, \mathrm{n}=852$ observations from 37 groups, Figure 1) but, as GAMMs rely on approximation, only probabilities less than 0.01 provide strong evidence of an effect (Zuur et al. 2009). The smoothed term is highly significant $\left(\mathrm{p}<1 \times 10^{-16}\right)$, and the model AIC without the smoothed term is much higher (Table 2), indicating the smoothed term is necessary. Residual plots confirmed the global model and end model were both good fits for the data.

\section{Latency to feed}

The global model had a brood size and parental sex interaction and a nestling condition and parental sex interaction. A random effect of nest did not change the AIC value (both equalled 236), but a linear mixed model was used anyway to give a conservative model. None of the variables had a significant effect on latency to feed and all dropped out of the model in backwards stepwise deletion (Likelihood ratio test: $\mathrm{p}>0.177)$.

\section{Parental distance from the nest with time after a predation threat}

Initially the pattern in the data was explored by via a GAMM. A GLMM (Generalised Linear Mixed Model) was considered suitable as the effective degrees of freedom (edf) from the GAMM was 1, which indicated that the data followed a linear trend. Ideally a binomial model should be used as the dependent variable is in the form of a proportion and therefore bounded between 0 and 1 . However, a binomial model gave warning messages due to the lack of variability in the data. Therefore, a Gaussian model was also fitted to confirm the results. For both models, the end results were qualitatively similar, therefore only the results of the Gaussian GLMM are reported.

The AIC was lower for a global GLMM model just with nest as a random effect as opposed to territory and year (-132 as opposed to -130$)$, both random effect models were better than a GLM without random effects (AIC $=-9.74)$. The AIC reduced when the sex and time since disturbance interaction was removed (AIC $=-145$ as opposed to -131 ). The amount of time that the parents spent within $20 \mathrm{~m}$ of the nest did not change significantly with increasing time since the nest disturbance event $(\mathrm{GLMM}$ : Est $=0.000446+/-0.000408, \mathrm{df}=0.0844, \mathrm{t}=1.09, \mathrm{p}=0.275, \mathrm{n}=885$ observations in 39 groups). Males spent significantly less time within $20 \mathrm{~m}$ of the nest than females (GLMM: Est = $0.0550+/-0.0143, \mathrm{df}=0.0855, \mathrm{t}=-3.85, \mathrm{p}=0.000125, \mathrm{n}=885$ observations in 39 groups). However, 
231 the magnitude of the difference was small, with males spending about $5 \%$ less time within $20 \mathrm{~m}$ of the

232 nest than females. The variance of the random intercept for nest was 0.0149 .

\section{Discussion}

234 Despite the study site consisting largely of unmanaged grassland, where researcher trails may be more 235 obvious compared to sites with shorter vegetation, monitoring visits to nests did not significantly 236 increase the chances of nest failure. This supports the findings from similar studies of ground-nesting 237 grassland birds (Cotter \& Gratto 1995; O’Grady et al. 1996; Lloyd et al. 2000; Jacobson et al. 2011).

238 Salisbury Plain supports large populations of other species of ground nesting birds including Meadow 239 Pipits, Skylarks, Yellowhammers and Reed Buntings (Stanbury et al. 2002, 2005) and there were 240 many other trails in the vegetation from related work on Whinchats and from other people such as 241 soldiers training, farmers, security forces and other researchers. Therefore, the predators may not have 242 learned to associate trails with nests (Hannon et al. 1993; O’Grady et al. 1996; Weidinger 2008). The 243 main predators of nests on Salisbury Plain were found to be nocturnal (Taylor et al. in prep), which 244 suggests mammalian predators. Various other studies have found that mammalian predators are 245 deterred by human scent trails and therefore visited nests are actually less likely to be predated 246 (Macivor et al. 1990; Ibanez-Alamo \& Soler 2010; Ibanez-Alamo et al. 2012). However, this pattern 247 was not observed in this study. The lack of organised predator control on Salisbury Plain, along with 248 the random nature of scent trails discussed above, could explain the lack of deterrence of mammals to 249 human scent trails. Alternatively, different predators may vary in their response to human scents, for 250 example with foxes deterred but stoats attracted, so thereby leading to no overall effect (Jacobson $e t$ 251 al. 2011).

252 Nest disturbance temporarily reduced the provisioning rate of parents; similar effects of disturbance 253 have been found in other studies (e.g. Delaney et al. 1999; Steidl \& Anthony 2000; Verhulst et al. 254 2001). This parental response is considered an adaptation to: reduce the risk of revealing the nest 255 location, allow more time to be invested in defence and vigilance behaviours, and reduce adult 256 predation risk (reviewed in Martin \& Briskie 2009 and Lima 2009). However, parental response to a 257 perceived predation risk can have real consequences on breeding success (Zanette et al. 2011).

258 It took approximately 20 minutes for the provisioning rate to recover, assuming the asymptote of the 259 NLS model (Table 1) represents the undisturbed provisioning rate. The mean provisioning rate 260 recorded for undisturbed nests of nestlings in approximately the same age range (5-8 days old), from 261 pilot data in 2012, was 1.35 feeds (95\% CI: $0.983-1.73, \mathrm{n}=16$ nests) in five minutes. The asymptote provisioning rate of 1.12 is within this range, therefore supporting this assumption. In an average summer day there are 960 minutes of daylight, therefore $2.08 \%$ of the day's provisioning is affected

264 by disturbance from a nest visit during the day. When not conducting the disturbance experiment, 
nests were visited three times in the $12-13$ days of the nestling period, which is 60 minutes of reduced provisioning out of 11520 minutes $(0.52 \%$ of the nestling period). The Whinchat parents may have reacted more strongly to disturbance in this experiment due to the presence of the camera and tripod at their nest in addition to the researcher visit, therefore this disturbance estimate is conservative. It does not appear that disturbance, at the level usually undertaken by researchers during the nestling phase in this project, would adversely affect offspring fitness.

Unlike results reported elsewhere, the change in the provisioning rate after disturbance and the latency to return to feed did not vary significantly with parent sex (Dale et al. 1996; Michl et al. 2000; Pavel \& Bures 2001; Zhao 2005), brood size (Tilgar \& Kikas 2009) or nestling condition (Michl et al. 2000). It is possible that this was due to the age of the nestlings used in the experiment. In Whinchats, parental care is female biased, with only females incubating the eggs and brooding the nestlings, though both sexes provision the nestlings (Cramp 1988). Therefore, nestlings may have more reproductive value to the female early in life than the male. The pilot data from 2012 suggested that the males' proportional investment in the nestlings (reflected in his provisioning behaviour) increased as they aged. Therefore by $6-9$ days old the nestlings are probably equally valuable to both parents (as also suggested by Tilgar \& Kikas 2009). The lack of an effect of nestling condition and brood size on the provisioning rate and latency to feed may be due to a lack of variation in nestling condition on Salisbury Plain as food does not appear to be limiting at the site (Taylor et al. in prep). If this study was conducted on a site with larger variations in nestling condition, a difference in risk taking for different quality broods (Michl et al. 2000; Tilgar \& Kikas 2009) may have been apparent.

The percentage of time the parents spent $20 \mathrm{~m}$ or closer to the nest did not vary significantly with time since the nest disturbance event. Parents generally always spent a high percentage of their time (70 $80 \%$ ) within $20 \mathrm{~m}$ of the nest. Preliminary analysis using the actual distances of parents from the nest, rather than the percentage of time parents spent within $20 \mathrm{~m}$, also found no change in the mean distance over time. As food appears to be relatively abundant on the study site, the parents may not need to travel far from the nest to forage (Andersson 1981), allowing them to spend most of their time close to the nest and thereby be able to guard the nest more effectively (Marzluff 1985; Martindale 1982; Hakkarainen et al. 2002; reviewed in Lima 2009). Whinchats cannot aggressively defend their nests from approaching humans, or other predators, by attacking. However, they do use alarm calling and perching in close proximity to the approaching individual to quiet their young and as distraction techniques (Montgomerie \& Weatherhead 1988; Caro 2005; Lima 2009). The change in provisioning pattern suggests Whinchats did spend a larger proportion of their time exhibiting nest guarding or vigilance behaviours immediately after a nest disturbance event, rather than foraging to provision nestlings, and then this reduced over time leading to an increased provisioning rate (reviewed in Frid \& Dill 2002, Price 2008 and Lima 2009). 
From this study we have found that nest monitoring visits every two to three days are not detrimental to Whinchat breeding success. Visits did not significantly affect the egg phase DSR and though parental provisioning rates were reduced for about 20 minutes following the disturbance, this equates to only $0.52 \%$ of the available foraging time during the nestling phase and therefore is unlikely to have a severe impact on nestling development. This is reassuring as it suggests that routine monitoring activities did not affect the outcome of nesting attempts. However, it is still important to take precautions to minimise any potential impact (Jacobson et al. 2011; Reynolds \& Schoech 2012) and follow guidelines for nest monitoring (Martin \& Geupel 1993; Ferguson-Lees et al. 2011). Depending on the research aims, it may be possible to use temperatures sensors placed in nest cups to monitor clutch and brood survival, reducing the number of visits necessary (Hartman \& Oring 2006; Weidinger 2006; Jacobson et al. 2011; Mougeot et al. 2014), or to monitor using micro-nest cameras which has the added advantage of identifying the nest predators (Pietz \& Granfors 2000).

\section{References}

Andersson, M. 1981. Central Place Foraging in the Whinchat, Saxicola rubetra. Ecology, 62: 538544.

Beale, C. M. \& Monaghan, P. 2004. Human disturbance: people as predation-free predators? Journal of Applied Ecology, 41: 335-343.

Bures, S. \& Pavel, V. 2003. Do birds behave in order to avoid disclosing their nest site? Bird Study, 50: 73-77.

Burhans, D. E. 2000. Avoiding the nest: responses of field sparrows to the threat of nest predation. The Auk, 117: 803-806.

Caro, T. 2005. Antipredator defenses in birds and mammals. University of Chicago Press. Chicago.

Chambers, J. M. 1992. Linear models. In Chambers, J. M., Hastie, T. J. eds. Statistical Models. Wadsworth \& Brooks/Cole, Michigan.

Clark, C. W. \& Ydenberg, R. C. 1990. The risks of parenthood .1. General-theory and applications. Evolutionary Ecology, 4: 21-34.

Cotter, R. C. \& Gratto, C. J. 1995. Effects of nest and brood visits and radio transmitters on rock ptarmigan. Journal of Wildlife Management, 59: 93-98.

Cox, W. A., Pruett, M. S., Benson, T. J., Chiavacci, S. J., \& Thompson III, F. R. 2012. Development of camera technology for monitoring nests. Accessed at: http://digitalcommons.unl.edu/usgsnpwrc/250/

Cramp, S. 1988. Handbook of the birds of Europe, the Middle East and North Africa: the birds of the Western Palearctic. Volume V, Tyrant flycatchers to thrushes: Oxford University Press, Oxford. 
Dale, S., Gustavsen, R. \& Slagsvold, T. 1996. Risk taking during parental care: A test of three hypotheses applied to the pied flycatcher. Behavioral Ecology and Sociobiology, 39: 31-42.

Davies, J., Arthur, D. \& White, S. 2014. Effects of variation in breeding habitat on Ring Ouzel Turdus torquatus productivity and nestling condition. Bird Study, 61: 162-170.

Delaney, D. K., Grubb, T. G., Beier, P., Pater, L. L. \& Reiser, M. H. 1999. Effects of helicopter noise on Mexican spotted owls. Journal of Wildlife Management, 63: 60-76.

Eggers, S., Griesser, M. \& Ekman, J. 2005. Predator-induced plasticity in nest visitation rates in the Siberian jay (Perisoreus infaustus). Behavioral Ecology, 16: 309-315.

Eggers, S., Griesser, M. \& Ekman, J. 2008. Predator-induced reductions in nest visitation rates are modified by forest cover and food availability. Behavioral Ecology, 19: 1056-1062.

Ferguson-Lees, J., Castell, R., Leech, D. 2011. A Field Guide to Monitoring Nests. British Trust for Ornithology. Thetford.

Frid, A. \& Dill, L. 2002. Human-caused disturbance stimuli as a form of predation risk. Conservation Ecology, 6: 11.

Ghalambor, C. K., Peluc, S. I. \& Martin, T. E. 2013. Plasticity of parental care under the risk of predation: how much should parents reduce care? Biology Letters, 9: 20130154.

Götmark, F. 1992. The effects of investigator disturbance on nesting birds. Pp. 63-104, in Current ornithology. Springer US, New York.

Green, A. J. 2001. Mass/length residuals: Measures of body condition or generators of spurious results? Ecology, 82: 1473-1483.

Hakkarainen, H., Yli-Tuomi, I., Korpimaki, E. \& Ydenberg, R. 2002. Provisioning response to manipulation of apparent predation danger by parental Pied Flycatchers. Ornis Fennica, 79: 139-144.

Hannon, S. J., Martin, K., Thomas, L. \& Schieck, J. 1993. Investigator disturbance and clutch predation in Willow Ptarmigan- methods for evaluating impact. Journal of Field Ornithology, 64: $575-586$.

Hartman, C. A. \& Oring, L. W. 2006. An inexpensive method for remotely monitoring nest activity. Journal of Field Ornithology, 77: 418-424.

Ibanez-Alamo, J. D. \& Soler, M. 2010. Investigator activities reduce nest predation in blackbirds Turdus merula. Journal of Avian Biology, 41: 208-212.

Ibanez-Alamo, J. D., Sanllorente, O. \& Soler, M. 2012. The impact of researcher disturbance on nest predation rates: a meta-analysis. Ibis, 154: 5-14.

Ibanez-Alamo, J. D. \& Soler, M. 2012. Predator-induced female behavior in the absence of male incubation provisioning: an experimental study. Behavioral Ecology and Sociobiology, 66: 1067-1073. 
Ippi, S., Dongen, W. F., Lazzoni, I., Venegas, C. I., \& Vásquez, R. A. 2013. Interpopulation comparisons of antipredator defense behavior of the Thorn-Tailed Rayadito (Aphrastura spinicauda). Ethology, 119: 1107-1117.

Jacobson, M. D., Tsakiris, E. T., Long, A. M. \& Jensen, W. E. 2011. No evidence for observer effects on Lark Sparrow nest survival. Journal of Field Ornithology, 82: 184-192.

Lima, S. L. 2009. Predators and the breeding bird: behavioral and reproductive flexibility under the risk of predation. Biological Reviews, 84: 485-513.

Lloyd, P., Little, R. M. \& Crowe, T. M. 2000. Investigator effects on the nesting success of arid-zone birds. Journal of Field Ornithology, 71: 227-235.

Macivor, L. H., Melvin, S. M. \& Griffin, C. R. 1990. Effects of research activity on piping plover nest predation. Journal of Wildlife Management, 54: 443-447.

Major, R. E. 1990. The effect of human observers on the intensity of nest predation. Ibis, 132: 608612.

Martin, T. E. 1987. Food as a Limit on Breeding Birds: A Life-History Perspective. Annual Review of Ecology and Systematics, 18: 453-487.

Martin, T. E. \& Briskie, J. V. 2009. Predation on Dependent Offspring A Review of the Consequences for Mean Expression and Phenotypic Plasticity in Avian Life History Traits. Year in Evolutionary Biology 2009, 1168: 201-217.

Martin, T. E. \& Geupel, G. R. 1993. Nest-monitoring plots- methods for locating nests and monitoring success. Journal of Field Ornithology, 64: 507-519.

Martindale, S. 1982. Nest defense and central place foraging - a model and experiment. Behavioral Ecology and Sociobiology, 10: 85-89.

Marzluff, J. M. 1985. Behavior at a pinyon jay nest in response to predation. Condor, 87: 559-561.

Michl, G., Torok, J., Garamszegi, L. Z. \& Toth, L. 2000. Sex-dependent risk taking in the collared flycatcher, Ficedula albicollis, when exposed to a predator at the nestling stage. Animal Behaviour, 59: 623-628.

Montgomerie, R. D. \& Weatherhead, P. J. 1988. Risks and rewards of nest defense by parent birds. Quarterly Review of Biology, 63: 167-187.

Mougeot, F., Benitez-Lopez, A., Casas, F., Garcia, J. T. \& Vinuela, J. 2014. A temperature-based monitoring of nest attendance patterns and disturbance effects during incubation by groundnesting sandgrouse. Journal of Arid Environments, 102: 89-97.

Mutzel, A., Blom, M. P. K., Spagopoulou, F., Wright, J., Dingemanse, N. J. \& Kempenaers, B. 2013. Temporal trade-offs between nestling provisioning and defence against nest predators in blue tits. Animal Behaviour, 85: 1459-1469.

O'Grady, D. R., Hill, D. P., \& Barclay, R. M. 1996. Nest Visitation by Humans Does Not Increase Predation on Chestnut-Collared Longspur Eggs and Young (Visitación de Nidos de Calcarius 
ornatus por Humanos no Aumenta la Depredación de sus Huevos y Pichones). Journal of Field Ornithology, 67: 275-280.

Paclik, M., Misik, J. \& Weidinger, K. 2012. Compensation for predator-induced reduction in nestling provisioning rate in the Great Spotted Woodpecker. Journal of Ethology, 30: 167-172.

Pavel, V. \& Bures, S. 2001. Offspring age and nest defence: test of the feedback hypothesis in the meadow pipit. Animal Behaviour, 61: 297-303.

Piatt, J. F., Roberts, B. D., Lidster, W. W., Wells, J. L. \& Hatch, S. A. 1990. Effects of human disturbance on breeding least and crested Auklets at St-Lawrence-Island, Alaska. Auk, 107: 342-350.

Pietz, P. J. \& Granfors, D. A. 2000. Identifying predators and fates of grassland passerine nests using miniature video cameras. Journal of Wildlife Management, 64: 71-87.

Price, M. 2008. The impact of human disturbance on birds: a selective review. In Lunney, D., Munn, A., Meikle, W. eds. Too Close for Comfort : Contentious Issues in Human-Wildlife Encounters. Royal Zoological Society of New south Wales, Mosman, pp 163-196.

R Development Core Team. 2014. R: A language and environment for statistical computing. R Foundation for Statistical Computing, Vienna, Austria. ISBN 3-900051-07-0, URL http://www.R-project.org/.

Reynolds, S. J. \& Schoech, S. J. 2012. A known unknown: elaboration of the observer effect' on nest success? Ibis, 154: 1-4.

Scheuerlein, A. \& Gwinner, E. 2006. Reduced nestling growth of East African Stonechats Saxicola torquata axillaris in the presence of a predator. Ibis, 148: 468-476.

Shaffer, T. L. 2004. A unified approach to analyzing nest success. Auk, 121: 526-540.

Skagen, S. K., Stanley, T. R. \& Dillon, M. B. 1999. Do mammalian nest predators follow human scent trails in the shortgrass prairie? Wilson Bulletin, 111: 415-420.

Stanbury, A., Branston, T., Sheldrake, P., Wilson, S. 2002. Breeding bird survey of Salisbury Plain training area. wpo/np/salispl/5037.RSPB and Defence Estates, Salisbury Plain.

Stanbury, A., Aspey, N., Moody, A., Vafidis, J. 2005. Breeding bird survey of the army training estate Salisbury Plain 2005. RSPB and Defence Estates, Salisbury Plain.

Steidl, R. J. \& Anthony, R. G. 2000. Experimental effects of human activity on breeding Bald Eagles. Ecological Applications, 10: 258-268.

Strang, C. A. 1980. Incidence of avian predators near people searching for waterfowl nests. Journal of Wildlife Management, 44: 220-222.

Thomson, R. L., Forsman, J. T., Monkkonen, M., Hukkanen, M., Koivula, K., Rytkonen, S. \& Orell, M. 2006. Predation risk effects on fitness related measures in a resident bird. Oikos, 113: 325333.

Tilgar, V. \& Kikas, K. 2009. Is parental risk taking negatively related to the level of brood reduction? An experiment with pied flycatchers. Animal Behaviour, 77: 43-47. 
Tilgar, V., Moks, K. \& Saag, P. 2011. Predator-induced stress changes parental provisioning behavior in pied flycatchers. Behavioral Ecology, 22: 23-28.

Tremblay, J. \& Ellison, L. N. 1979. Effects of human disturbance on breeding of Black-Crowned Night Herons. Auk, 96: 364-369.

Trivers, R. L. 1972. Parental investment and sexual selection. Pp. 136-179, in Campbell, B. ed. Sexual Selection and the Descent of Man. Heinemann, London.

Verhulst, S., Oosterbeek, K. \& Ens, B. J. 2001. Experimental evidence for effects of human disturbance on foraging and parental care in oystercatchers. Biological Conservation, 101: 375-380.

Vitousek, M. N., Jenkins, B. R., \& Safran, R. J. 2014. Stress and success: Individual differences in the glucocorticoid stress response predict behavior and reproductive success under high predation risk. Hormones and Behavior, 66: 812-819.

Walker, K.J. and Pywell, R.F. 2000. Grassland communities on Salisbury Plain Training Area SPTA.: results of the ITE ecological survey. Wiltshire Botany, 3: 15-27.

Weidinger, K. 2006. Validating the use of temperature data loggers to measure survival of songbird nests. Journal of Field Ornithology, 77: 357-364.

Weidinger, K. 2008. Nest monitoring does not increase nest predation in open-nesting songbirds: inference from continuous nest-survival data. Auk, 125: 859-868.

Wheelwright, N. T., \& Dorsey, F. B. 1991. Short-term and long-term consequences of predator avoidance by Tree Swallows (Tachycineta bicolor). The Auk, 108: 719-723.

Whelan, C. J., Dilger, M. L., Robson, D., Hallyn, N. \& Dilger, S. 1994. Effects of olfactory cues on artificial-nest experiments. Auk, 111: 945-952.

Woodcock, B. A., Pywell, R. F., Roy, D. B., Rose, R. J. \& Bell, D. 2005. Grazing management of calcareous grasslands and its implications for the conservation of beetle communities. Biological Conservation, 125: 193-202.

Zanette, L. Y., White, A. F., Allen, M. C. \& Clinchy, M. 2011. Perceived Predation Risk Reduces the Number of Offspring Songbirds Produce per Year. Science, 334: 1398-1401.

Zhao, L. 2005. Behavioral responses of two species passerine to predation risk during breeding period. Zoological Research, 26: 113-117.

Zuur, A., Ieno, E. N., Walker, N., Saveliev, A. A. \& Smith, G. M. 2009. Mixed Effects Models and Extensions in Ecology with R: Springer, New York. 


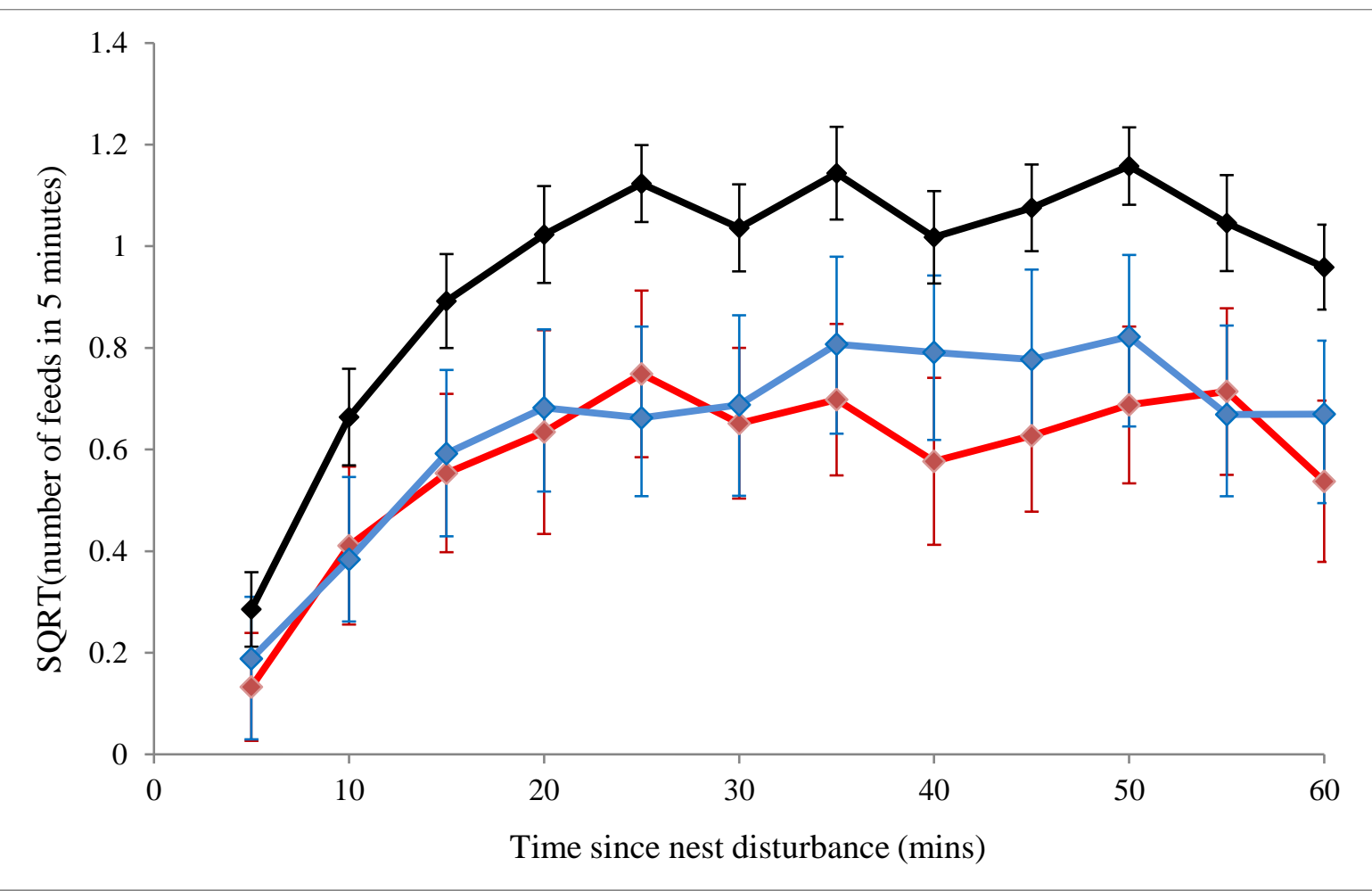

475 Figure 1. The square rooted mean number of feeds for all feeds (black), males (blue) and females (red) 476 over all nests in each 5 minute period since the nest disturbance event up to 60 minutes ( $\mathrm{n}=36$ females, $477 \mathrm{n}=35$ males, but from 37 different nests as one nest only had a male parent and two only had female 478 parents). The bars display the $95 \%$ confidence intervals. 
481 Table 1. An NLS model of the change in square rooted provisioning rate per five minute block, with 482 time since a nest disturbance event. Nest was a random effect, there were 37 groups with a total of 444 483 observations. The model $\log$ likelihood $=-304.1$, deviance $=608$, residual $\mathrm{df}=439$, the standard 484 deviation of the random asymptote for each territory is 0.298 . The model equation: square rooted 485 number of feeds in 5 minutes $=1.06 /(1+\exp ((8.12$-time since nest disturbance $) / 3.45))$.

486

\begin{tabular}{lc}
\hline & Parameters estimates \\
\hline Asymptote & $1.06+/-0.004$ \\
Midpoint & $8.12+/-0.004$ \\
Slope & $3.45+/-0.004$ \\
\hline
\end{tabular}

487

488

489 
Table 2. Model selection for a GAMM looking at the variation in response to nest disturbance through 491 provisioning rate, due to differences of parental sex or in average nestling condition at 6 days old. Brood 492 size was included in all models to control for any effect of variation in brood size between nests (3 nests 493 of 3, 7 nests of 4, 8 nests of 5 and 19 nests of 6) on the provisioning rate. Nest was included as a random 494 effect to account for repeated measures of provisioning rate, which was calculated for 12 five minute 495 periods for each nest. Time $=$ time since nest disturbance by the researcher, condition $=$ average nestling 496 condition for a nest when the nestlings were 6 days old, $\mathrm{S}=$ a smoother term, sex $=$ male or female 497 parent, : = interaction effect. $\mathrm{N}=852$ observations from 37 nests.

\begin{tabular}{ll}
\hline Model & AIC \\
\hline S(time) + sex + brood size & 1038 \\
S(time) + sex + condition + brood size & 1040 \\
S(time) +sex : condition + brood size & 1042 \\
S(time) + brood.size & 1042 \\
S(time : sex $)+$ sex : condition + brood size & 1052 \\
Time + sex + brood size & 1089 \\
Sex + brood size & 1139 \\
\hline
\end{tabular}

498 


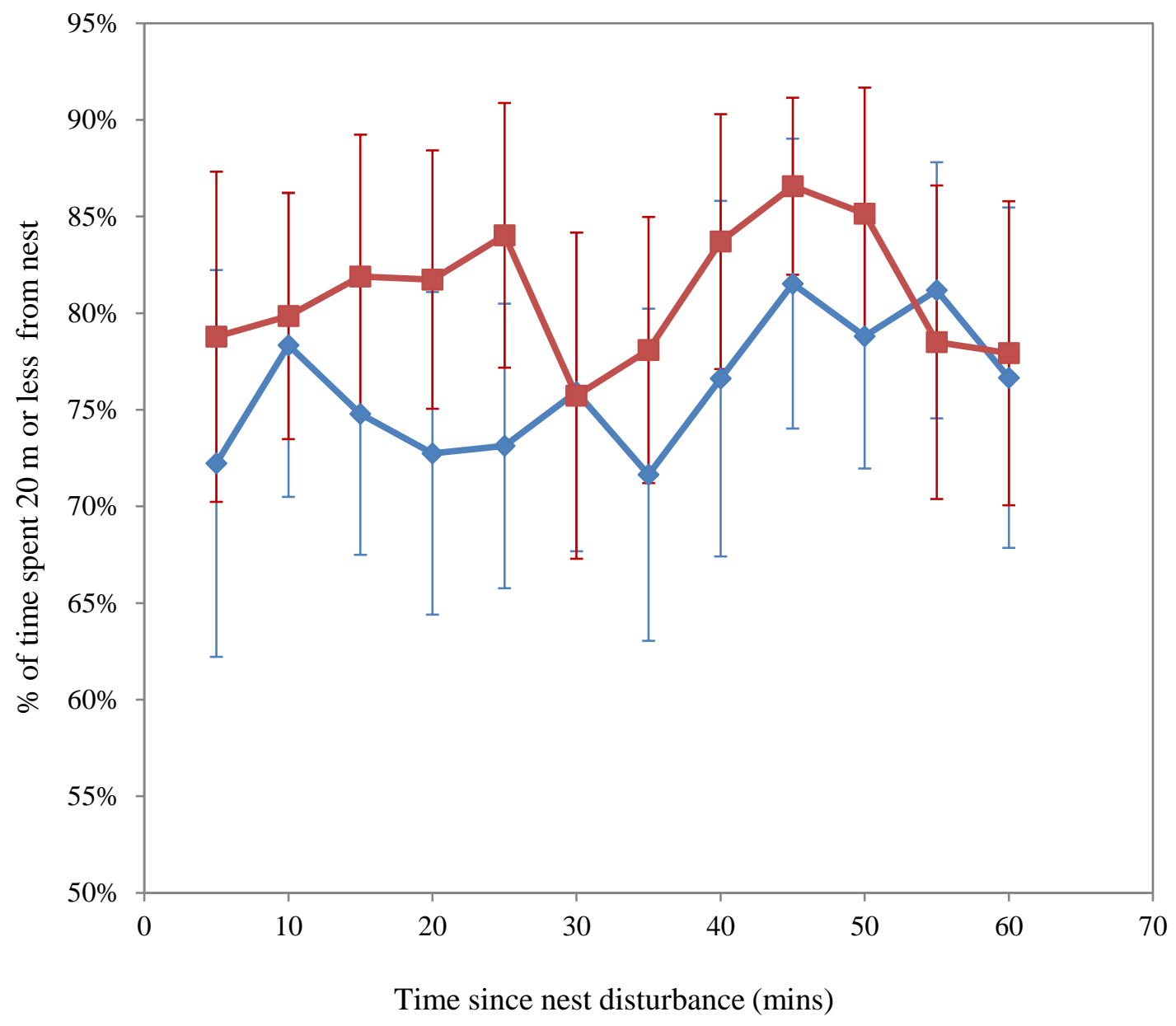

502 Figure 2. The mean percentage of time spent within $20 \mathrm{~m}$ of the nest for males (blue), and females 503 (red), with increasing time since a nest disturbance event. The bars display the $95 \%$ confidence intervals $504 \quad(\mathrm{n}=885$ observations in 39 groups $)$. 


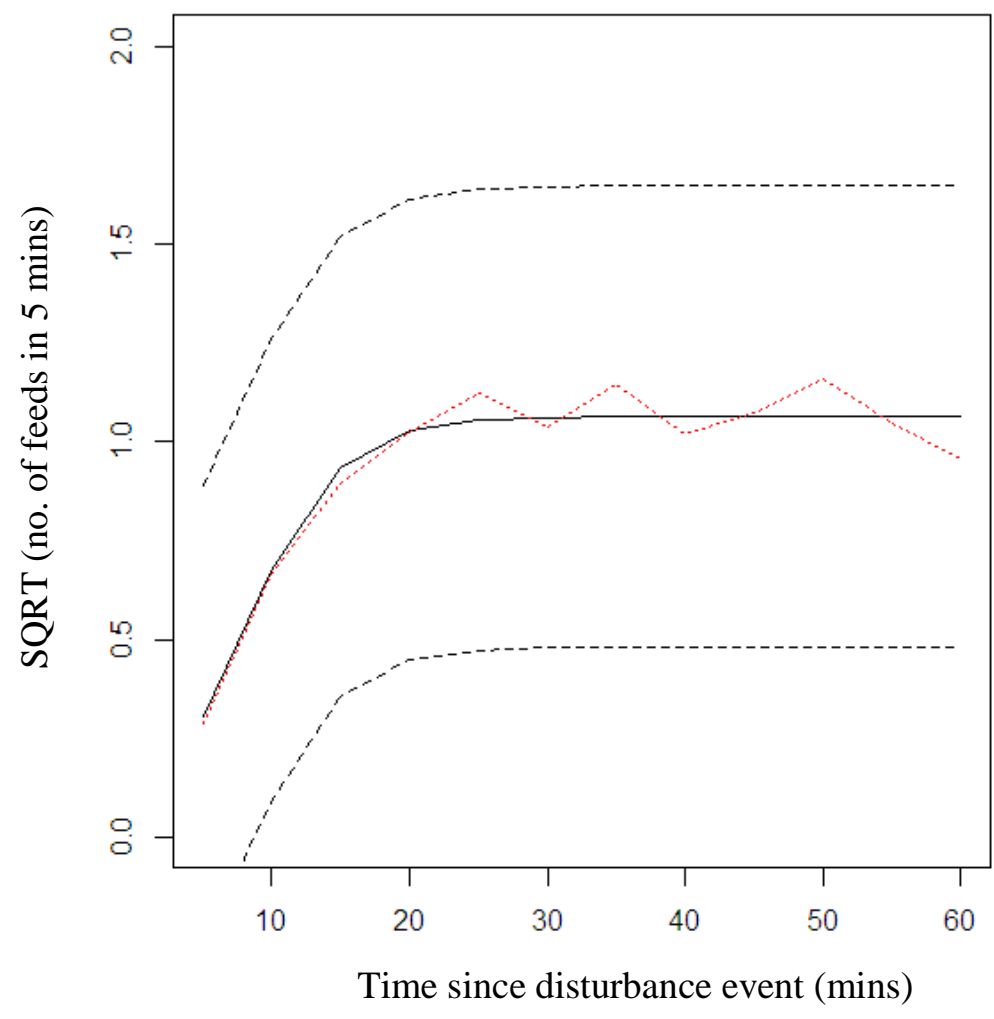

506

507 S1. An asymptotic random effects NLS model of the change in provisioning rate per five minute block 508 with time since a nest disturbance event, the solid line is the value for an average nest, $95 \%$ of nests are 509 within the dotted lines ( $\mathrm{n}=444$ in 37 groups). The red line is the square-rooted mean provisioning rates per 5 minutes block from the raw data. 